\title{
Melatonin: the Weapon Against Oxidative Stress and Nitrosative Stress in Neurovascular Diseases
}

\author{
Muhammad Masood Ahmed, Ji-Yun Huang, Rong-rong Tao and Feng Han* \\ Institute of Pharmacology, Toxicology and Biochemical Pharmaceutics, Zhejiang University, Hangzhou, China
}

\begin{abstract}
The multiple lines of evidence demonstrate that melatonin exerts powerful antioxidant actions by preventing and scavenging free radicals in a direct and indirect manner. Importantly, melatonin reduced post-ischemic oxidative/ nitrosative damage to the afflicted neurovascular units and improved the preservation of blood-brain barrier permeability in various brain diseases. The information compiled here will serve as a comprehensive reference for the neurovascular protective actions of melatonin to date, and will hopefully help to design further experimental research and expand melatonin as neurovascular protective agent in neurovascular diseases.
\end{abstract}

Keywords: Melatonin; Nitrosative stress; Oxidative stress; Bloodbrain barrier; Neurovascular protection

Abbreviations: AD: Alzheimer's disease; AFMK: $\mathrm{N}^{1}$-acetyl$\mathrm{N}^{2}$-formyl-5-methoxy-kynuramine; cAMP: cyclic adenosine monophosphate; $\mathrm{Ca}^{2+} / \mathrm{CaM}$ : Calcium/Calmodulin; cGMP: cyclic guanosine monophosphate; eNOS: endothelial nitric oxide synthase; GSH-Px: glutathione peroxidase; $\mathrm{H}_{2} \mathrm{O}_{2}$ : hydrogen peroxide; HIOMT: hydroxyindole-O-methyl transferase; HtrA2-PED: HtrA serine peptidase 2; Keap1/Nrf2: Kelch-like ECH-associated protein 1/ nuclear factor (erythroid-derived 2)-like 2; MPTP: 1-methyl-4-phenyl-1,2,3,6tetrahydropyridine ; NMDA: N-methyl-D-aspartate; NO: nitric oxide; $\mathrm{ONOO}^{-}$: peroxinitrite anion; OGD: oxygen-glucose deprivation; PD: Parkinson's disease; RNS: reactive nitrogen species; ROS: reactive oxygen species; SNAT: serotonin $\mathrm{N}$-acetyltransferase; $\mathrm{VaD}$ : vascular dementia; VCM's: vacuous chewing movements; ZO-1: zonula occludens-1

\section{Introduction}

Melatonin (N-acetyl-5-methoxytryptamine) is naturally occurring compound synthesized from serotonin in the pineal gland of mammals. It has been widely accepted that the primary physiological function of pineal melatonin secretion is to convey information about daily cycles of light and darkness to body physiology [1,2]. Beyond its physiological role in allowing the entrainment of the circadian rhythms, multiple lines of evidence demonstrate that melatonin also exerts a powerful antioxidant action by preventing and scavenging free radicals in a direct and indirect manner [3].

Cerebrovascular abnormalities contribute to the pathogenesis of ischemic stroke, Alzheimer's disease (AD), and vascular dementia (VaD) [1-4]. Stroke is an acute-onset cerebrovascular incident that can result in neurological deficits due to the impairment of cerebral circulation via microvascular injury [5-9]. Indeed, microvascular injury mechanisms may precede, exaggerate, or contribute to the progression of neurodegenerative disorders. The abnormal ion channel activations, intracellular overload with calcium and radical oxidative stresses participate in the pathological process of neurovascular damage $[3,10,11]$

The pharmacological effects of melatonin on neurovascular diseases have been currently supported by experimental and clinical data, including antioxidant, anti-inflammatory and anti-excitotoxic properties as well as prevent mitochondrial impairment, energy failure, and apoptosis in brain diseases. Notably, melatonin is highly effective as calmodulin antagonist [12-15], a free radical scavenger [16-19] and has also been shown to exert neurovascular protective effects on brain pathologies [3]. This article summarizes the current understanding of the role and mechanisms of melatonin in neurovascular diseases.

\section{Melatonin and Neurovascular Diseases}

Studies show that Melatonin is synthesized by two enzymatic steps from serotonin. The first is the $\mathrm{N}$-acetylation by serotonin $\mathrm{N}$-acetyltransferase (SNAT) to yield $\mathrm{N}$-acetylserotonin. The second step in melatonin synthesis is the transfer of a methyl group from $\mathrm{S}$-adenosylmethionine to the 5-hydroxy group of $\mathrm{N}$-acetylserotonin to yield melatonin and reaction catalyzed by the hydroxyindole-Omethyl transferase (HIOMT) [1,2,20,21]. Besides directly neutralizing a variety of reactive oxygen and reactive nitrogen species, melatonin is a potent free radical scavenger [22]. In specific reference to the brain, melatonin also has an advantage over some other antioxidants because it readily passes through the blood-brain barrier (BBB). Indeed, it has been shown by therapeutic trials that melatonin is effective in reducing oxidative damage and slowing the progression of neurovascular diseases [23-26].

\section{Melatonin and brain ischemia}

Brain stroke, is the third largest cause of mortality and is the single largest cause of adult disability [27]. Ischemic stroke, a significant cause of neurovascular dysfunction can result in cerebral hypoperfusion and leading to death of brain tissues within minutes to hours. The emerging epidemiological and clinical evidence indicates that oxidative and nitrosative stress is involved in the pathogenesis of ischemic complications $[23,28]$.

Manev et al. demonstrated the direct evidence that endogenous

*Corresponding author: Feng Han, Institute of Pharmacology, Toxicology and Biochemical Pharmaceutics, Zhejiang University, China, Tel: 86-571-8820-8402; Fax: 86-571-8820-8402; E-mail: changhuahan@zju.edu.cn

Received November 15, 2012; Accepted November 22, 2012; Published Novemebr 26, 2012

Citation: Ahmed MM, Huang JY, Tao RR, Han F (2012) Melatonin: the Weapon Against Oxidative Stress and Nitrosative Stress in Neurovascular Diseases. J Bioanal Biomed S5: 005. doi:10.4172/1948-593X.S5-005

Copyright: (c) 2012 Ahmed MM, et al. This is an open-access article distributed under the terms of the Creative Commons Attribution License, which permits unrestricted use, distribution, and reproduction in any medium, provided the original author and source are credited. 
melatonin may play a neuroprotective role and melatonin deficiency leads to increased brain vulnerability in focal brain ischemia model [28]. By using transient bilateral carotid artery ligation model, Guerrero et al. reported that melatonin prevents the increase in NO and cGMP production in brain is responsible for the protective effect of melatonin on neuronal structures during transient ischemia [29]. Moreover, melatonin protects against ischemia/reperfusion-induced damage to mitochondria in the fetal rat brain [30]. In in vitro oxygen-glucose deprivation (OGD) model, melatonin pretreatment significantly inhibited OGD-induced peroxinitrite formation and prevented a substantial imbalance in mitochondrial HtrA2-PED signaling as well as increase the endothelial cell survival rate after ischemia-like injury $[14,31,32]$. The BBB preserves the delicate homeostasis of the brain microenvironment through the maintenance of tight junctions between brain vascular endothelial cells. Brain edema formation and subsequently neuronal death due to loss of integrity of the BBB is a major consequence of cerebral ischemia [33-37]. Indeed, melatonin treatment is highly effective in decreasing the late increase in BBB permeability and the risk of tissue plasminogen activator in excitotoxicity or brain ischemia/reperfusion models $[28,38,39]$. Moreover, weak or irregular expression of zipper-like ZO-1 immunoreactivity was observed in OGD-treated cells compared with controls, and this decrease was markedly reduced by melatonin pretreatment [32].

\section{Melatonin and Alzheimer's disease}

Alzheimer's disease (AD) is characterized by progressive loss of cognition, loss of memory and other neurobehavioral manifestations. More than one third of $\mathrm{AD}$ patients exhibit variable cerebrovascular pathology and white matter injury, indicating the association of cerebrovascular risk factors with AD. In addition, oxidative stress, nitrosative stress and mitochondrial dysfunction have been implicated in the progression of $\mathrm{AD}$.

In rodent model of $\mathrm{AD}$, melatonin reduced plasma homocysteine and lipid levels, and the investigators suggested that the melatonin's antioxidant effects may have been responsible for these results [4042]. Oxidative stress in $\mathrm{AD}$ is the result of decline in the production of endogenous melatonin and an imbalance in pro-oxidant/antioxidant homeostasis that leads to the overgeneration of toxic reactive oxygen species $[43,44]$. Melatonin prevents the death of neuroblastoma cells exposed to $\beta$-amyloid polypeptide [45-47]. Moreover, melatonin has exhibited neuroprotective and antioxidant properties against $\beta$-amyloid mediated oxidative injury in vitro $[14,46,48]$, which may be associated with the inhibitory effect of melatonin on the formation of $\beta$-sheets and amyloid fibrils [49]. The unique feature of melatonin and its protective metabolites regarding $\mathrm{AD}$ is the ability to interact directly with the electron transport chain by increasing the electron flow as well as antagonizes formation of superoxide anions and $\beta$-amyloid toxicity $[44,45,50,51]$. Furthermore, there is evidence to suggest that melatonin administration to $\mathrm{AD}$ transgenic mice is associated with a reduction in a number of important disease markers, including $\beta$-amyloid levels, protein tyrosine nitration and reduced life expectancy $[46,47,52]$.

\section{Melatonin and Parkinson's disease}

Parkinson's disease $(\mathrm{PD})$ is a neurodegenerative disorder due to degeneration of dopaminergic neurons in the substantia nigra [53-56]. It has been reported regarding PD etiology that oxidative stress with reduced glutathione peroxidase while the level of the antioxident enzyme manganese superoxide dismutase is high and not paralleled by glutathione levels $[57,58]$. The accumulating evidences demonstrated that radical damage in lipids [59], proteins [60], and nucleic acids [61] of substantia nigra in parkinsonian patients. Studies show that dopaminergic neurons are susceptible to increase reactive oxygen species [62], while amines derive radical formation results in auto oxidation of dopamine. Recently it has been studied that mitotochondrial dysfunction can lead to aggregation of a-synuclein might be a reason for neurodegeneration $[23,63]$. Further it has been reported that increase in iron level [64] catalyzes the fenton reaction [65] leading to metal induced lipid peroxidation [66] via hydroxyl radical generation. Animal models with altered dopaminergic function have been used to study efficacy of various therapeutic agents in the treatment of Parkinson's disease [67].

Antolin and his co-workers found that melatonin was effective in preventing neuronal cell death and 1-methyl-4-phenyl-1,2,3,6tetrahydropyridine (MPTP) induced damage to the substantia nigra in experimental parkinsonism [53,68]. MPTP and 6-OHDA models of PD showed that melatonin's antioxidant effect is able to counteract MPTP induced lipid peroxidation in striatum, hippocampal, and midbrain regions $[5,69,70]$. Melatonin inhibited neuronal excitation caused by NMDA activation in rat striatum [71]. The negative interaction between dopaminergic and adenosinergic system in striatum has been ameliorated by melatonin in ferric chloride induced model of experimental PD [72]. In addition, melatonin reversed vacuous chewing movements (VCM's) in rats, chronically treated with haloperidol as well as melatonin has role for the prevention and treatment of neuroleptic induced orofacial dyskinesia [73]. MPTP, through its metabolite $\mathrm{MPP}^{+}$inhibits the complex I of substantia nigra of PD patients. Intriguingly, melatonin exerts antioxidant effect by increasing complex I and complex IV activities of mitochondrial electron transport chain $[74,75]$.

\section{Melatonin: A Weapon Against Oxidative and Nitrosative Stress}

Free radicals are highly reactive molecules generated during cellular respiration and normal metabolism. However, imbalance between cellular production of free radicals and the ability of cells to defend against them is referred to as oxidative stress [76]. In addition, reactive nitrogen species are powerful oxidizing and nitrating agents for cell damage, including the nitrogen dioxide radical $\left(\mathrm{NO}_{2}\right)^{-}$) and various non-free radicals, such as peroxynitrite $\left(\mathrm{ONOO}^{-}\right)$and its protonated form. The final products of oxidative and nitrosative stress are extremely aggressive oxidants, which is also a key factor of functional importance in driving neurovascular disease progression [32]. Brain is highly vulnerable to oxidative and nitrosative injury because of its high oxygen consumption, abundant lipid content, and the relative deficiency of antioxidant enzymes as compared with other tissues $[27,77,78]$. It has been indicated by evidence that the reactive nitrogen species contribute to early injury of neurovascular endothelial cells, which is also of key importance in neurovascular diseases $[32,79]$. Notably, melatonin elicits neurovascular protective effect via its antioxidant and free-radical-scavenging capacities in brain diseases $[3,80]$.

\section{Mechanism of melatonin against oxidative stress}

A large body of evidence indicates that the scavenging potential of melatonin is mainly due to its antioxidative ability, may be defined as scavenging cascade reactions [22]. Melatonin showed its scavenging actions against peroxynitrite anion, singlet oxygen and nitric oxide, hydrogen peroxide as well as interacts with the highly toxic hydroxyl radical $[16,17,81]$. 
In vitro studies, Stasica et al. $[82,83]$ demonstrated that melatonin is a more efficient $\bullet \mathrm{OH}$ scavenger than either glutathione or mannitol, melatonin reacts at a diffusion-controlled rate with the $\bullet \mathrm{OH}[16,17]$. Melatonin scavenged $\mathrm{H}_{2} \mathrm{O}_{2}$ efficiently but only one molecule, $\mathrm{N}^{1}$-acetyl$\mathrm{N}^{2}$-formyl-5-methoxy-kynuramine (AFMK) with molecular mass 264 resulted by the interaction with $\mathrm{H}_{2} \mathrm{O}_{2}$ during proposed metabolic pathway [84]. It has been reported that melatonin can detoxify $\mathrm{O}_{2}$. to produce a kynuramine, a melatonyl radical which is formed when melatonin donates an electron, is recycled back to melatonin by both ascorbate or urate with equal efficiency [85-88]. In consequence, melatonin's ability to function as an anti-oxidant in virtually all parts of the cell and to protect membrane lipids, cytosolic proteins and nuclear DNA from oxidative damage [89]. The immunocytochemical data demonstrated that melatonin's immunoreactivity is certainly found in different subcellular compartments and plays a critical role as a bioenergetic agent $[90,91]$. The pathophysiological relevance of increased oxidative stress and the mitochondria-dependent apoptotic cascade has recently become a topic of interest. Importantly, melatonin can improve and maintain mitochondrial function during cellular degenerative processes via preventing protein oxidation, the mitochondrial permeability transition pore opening and the release of mitochondrial proteins [32,92].

Besides directly detoxifying a variety of reactive oxygen and reactive nitrogen species, other actions of melatonin, such as stimulation of antioxidative enzymes also improves its status as an antioxidant. Melatonin also induces or preserves the several intracellular antioxidant enzymes, including superoxide dismutase, glutathione peroxidase (GSH-Px), $\gamma$-glutamylcysteine synthetase as well as glutathione (GSH) $[93,94]$.

\section{Mechanism of melatonin against nitrosative stress}

Accumulating evidence supports the importance of the nitrosoredox balance in the pathogenesis of neurovascular complications. The formation of highly reactive nitrogen-containing molecules mediates protein oxidation and nitration, mitochondrial dysfunction, caspase-dependent apoptotic cascade, DNA damage [38,88,95,96]. We and others have previously reported that presence of nitrosative stress in endothelial cells/microvessels can damage biomolecules and subsequently cause the breakdown of highly-structured cellular machinery in the brain $[14,19]$. The accumulating data demonstrate that neutralization of $\mathrm{ONOO}^{-}$and/or pharmacological inhibition of nitrosative stress-related pathways will be therapeutically effective in a wide range of neurovascular diseases [32]. Importantly, melatonin scavenges a number of oxidants including the nitric acid, peroxynitrite $\left(\mathrm{ONOO}^{-}\right)$and peroxynitrous acid during pathological process of neurovascular diseases $[15,19,97]$.

The excessive $\mathrm{Ca}^{2+}$ influx into neurons also causes abnormal activation of $\mathrm{Ca}^{2+}$ dependent enzymes such as phospholipase $\mathrm{A}_{2}$, calpain and $\mathrm{Ca}^{2+} / \mathrm{Calmodulin}$ (CaM)-dependent enzymes [98-100]. Given that $\mathrm{Ca}^{2+} / \mathrm{CaM}$-dependent enzymes are important for ONOOformation, and melatonin has been reported to modulate the $\mathrm{Ca}^{2+} /$ CaM signaling pathway in various tissues $[12,13]$. In this regard, we have recently demonstrated that microvessel injury induced aberrant nitric oxide and peroxynitrite production in a CaM-dependent manner $[15,32,96]$. Additionally, recent reports have shown that melatonin can directly react and neutralize ONOO- $[19,18,97,101]$. Several studies suggested melatonin may have a role in the biological regulation of cerebrovascular disease probably via its effect on the nitric oxide $[29,96]$.

The melatonin significantly inhibited OGD-induced ONOO formation and caused a substantial imbalance in HtrA2-PED signaling a well as melatonin increased the survival rate of endothelial cells after ischemic-like injury [32]. Several studies suggested that the inhibitory effect of melatonin on nitric oxide synthase activity might be produced through a high affinity CaM-melatonin binding $[12,13,32,102]$. Pharmacological repression of ONOO formation by melatonin partially inhibited ischemia-induced protein tyrosine nitration of Keap1 as well as disturbance of Keap1/Nrf2 signaling in endothelial cells [103]. In addition, our group has found that activation of autophagy by OGD was partially inhibited in melatonin-treated cells, suggesting a critical role for nitrosative stress in the induction of autophagy by ischemic stress [96]. It has also been observed that the melatonin treatment effectively inhibited OGD-induced cathepsin $B$ activation, which indicates that an interaction exists between the autophagy-lysosome pathway and nitrosative stress [96]. It is also notable that melatonin administration prevented rigidity in the mitochondrial membrane and decrease age-related autophagylysosomal alterations [104]. Consistent with the suppression of autophagic signaling in eNOS knock-down cells, activation of the either autophagic or lysosome process by OGD was partially blocked in the melatonin-treated endothelial cells, suggesting a critical role for nitrosative stress in the induction of mitochondrial damage and autophagy process $[14,32]$. Thus, ischemic insult promotes the ONOO pathway and activates lysosomal signaling and that such activation can be inhibited by melatonin pretreatment. Nagai et al. [30] demonstrated that melatonin protects against ischemia/reperfusion-induced damage to mitochondria in the fetal rat brain. Most importantly, melatonin reduced tight junction protein breakdown in a brain ischemia model in close association with concomitant inhibition of nitrosative stress and protein tyrosine nitration $[14,32,105]$. Although the identities of target proteins that may be regulated by $\mathrm{ONOO}^{-}$remain to be defined in future studies, data derived from the present study raise the possibility that $\mathrm{ONOO}^{-}$targeting by melatonin may be a new strategy to prevent or treat neurovascular diseases.

\section{Concluding Remarks}

Although our knowledge about the crucial role of melatonin on various neurodegenerative disorders has advanced considerably in recent years, but several important issues remain to be resolved. For example, 1) It remains to be ascertained the role of MT1 or MT2 receptors on melatonin-mediated neurovascular protection. 2) There may be different dose requirements for different phase of neurovascular pathological conditions, understanding the appropriate dosage of melatonin will provide new insight to develop better neurovascular protective drugs. 3) There is also increasing interest in studying coadministration of melatonin with other therapeutic agents that may be even more effective in extending the therapeutic time window for neurovascular diseases.

To conclude, melatonin is a highly effective calmodulin antagonist and anti-oxidant, which directly scavenges a variety of oxygen- and nitrogen-based reactants, preserves the integrity of the mitochondria, stimulates antioxidative enzymes; eventually elicit its neurovascular protective effect (Figure 1). Finally, one might expect that the body of direct mechanistic and clinical data on melatonin and its derivatives 
Citation: Ahmed MM, Huang JY, Tao RR, Han F (2012) Melatonin: the Weapon Against Oxidative Stress and Nitrosative Stress in Neurovascular Diseases. J Bioanal Biomed S5: 005. doi:10.4172/1948-593X.S5-005

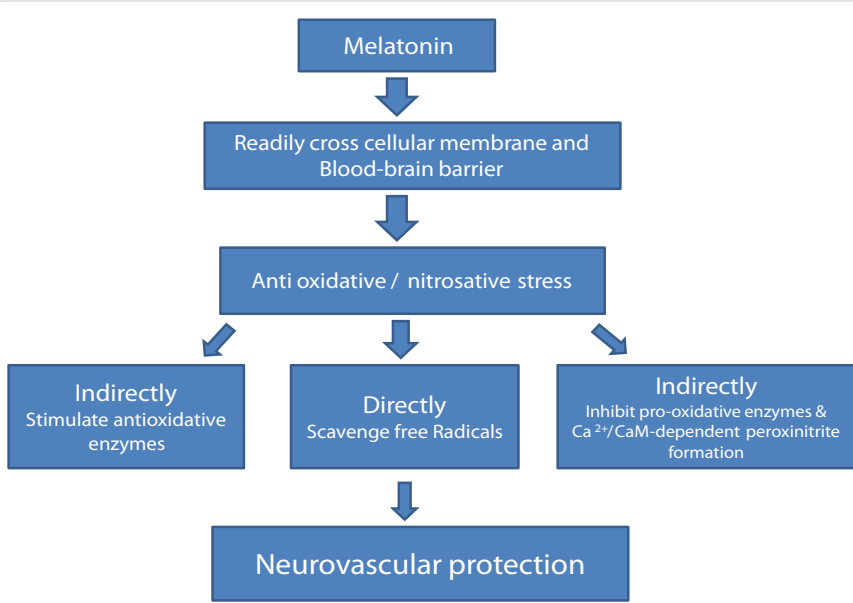

Figure 1: Diagrammatic representation of the inhibitory effect of melatonin on the oxidative/nitrosative stress-mediated neurovascular injury.

targeting the oxidative/nitrosative stress in the pathogenesis of neurovascular diseases may afford clinicians a new therapeutic armamentarium to treat patients with neurovascular disorders.

\section{References}

1. Claustrat B, Brun J, Chazot G (2005) The basic physiology and pathophysiology of melatonin. Sleep Med Rev 9: 11-24.

2. Cardinali DP, Pévet $P$ (1998) Basic aspects of melatonin action. Sleep Med Rev 2: $175-190$.

3. Reiter RJ, Acuña-Castroviejo D, Tan DX, Burkhardt S (2001) Free radicalmediated molecular damage. Mechanisms for the protective actions of melatonin in the central nervous system. Ann N Y Acad Sci 939: 200-215.

4. Acuna-Castroviejo D, Escames G, Rodriguez MI, Lopez LC (2007) Melatonin role in the mitochondrial function. Front Biosci 12: 947-963.

5. Mayo JC, Sainz RM, Tan DX, Antolín I, Rodríguez C, et al. (2005) Melatonin and Parkinson's disease. Endocrine 27: 169-178.

6. Reiter RJ, Tan DX, Leon J, Kilic U, Kilic E (2005) When melatonin gets on your nerves: its beneficial actions in experimental models of stroke. Exp Biol Med (Maywood) 230: 104-117

7. Wu YH, Swaab DF (2005) The human pineal gland and melatonin in aging and Alzheimer's disease. J Pineal Res 38: 145-152.

8. Siu AW, Maldonado M, Sanchez-Hidalgo M, Tan DX, Reiter RJ (2006) Protective effects of melatonin in experimental free radical-related ocular diseases. J Pineal Res 40: 101-109.

9. Maldonado MD, Murillo-Cabezas F, Terron MP, Flores LJ, Tan DX, et al. (2007) The potential of melatonin in reducing morbidity-mortality after craniocerebral trauma. J Pineal Res 42: 1-11.

10. Cheung RT (2003) The utility of melatonin in reducing cerebral damage resulting from ischemia and reperfusion. J Pineal Res 34: 153-160.

11. Reiter RJ, Tan DX, Pappolla MA (2004) Melatonin relieves the neural oxidative burden that contributes to dementias. Ann N Y Acad Sci 1035: 179-196.

12. Pozo D, Reiter RJ, Calvo JR, Guerrero JM (1997) Inhibition of cerebellar nitric oxide synthase and cyclic GMP production by melatonin via complex formation with calmodulin. J Cell Biochem 65: 430-442.

13. Bettahi I, Pozo D, Osuna C, Reiter RJ, Acuña-Castroviejo D, et al. (1996) Melatonin reduces nitric oxide synthase activity in rat hypothalamus. J Pineal Res 20: 205-210.

14. Tao RR, Ji YL, Lu YM, Fukunaga K, Han F (2012) Targeting nitrosative stress for neurovascular protection: new implications in brain diseases. Curr Drug Targets 13: $272-284$

15. Han F, Shirasaki Y, Fukunaga K (2006) Microsphere embolism-induced endothelial nitric oxide synthase expression mediates disruption of the bloodbrain barrier in rat brain. J Neurochem 99: 97-106.

16. Tan DX, Chen LD (1993) Melatonin: a potent, endogenous hydroxyl radica scavenger. Endocrine J 1: 57-60.

17. Poeggeler B, Reiter RJ (1996) Melatonin and structurally related, endogenous indoles act as potent electron donors and radical scavengers in vitro. Redox Rep 2: 179-184.

18. Gilad E, Cuzzocrea S, Zingarelli B, Salzman AL, Szabó C (1997) Melatonin is a scavenger of peroxynitrite. Life Sci 60: PL169-174.

19. Zhang H, Squadrito GL, Pryor WA (1998) The reaction of melatonin with peroxynitrite: formation of melatonin radical cation and absence of stable nitrated products. Biochem Biophys Res Commun 251: 83-87.

20. Klein DC, Moore RY (1979) Pineal N-acetyltransferase and hydroxyindoleO-methyltransferase: control by the retinohypothalamic tract and the suprachiasmatic nucleus. Brain Res 174: 245-262.

21. Bernard M, Guerlotté J, Grève P, Gréchez-Cassiau A, luvone MP, et al. (1999) Melatonin synthesis pathway: circadian regulation of the genes encoding the key enzymes in the chicken pineal gland and retina. Reprod Nutr Dev 39: 325 334.

22. Tan DX, Manchester LC, Reiter RJ, Qi WB, Karbownik M, et al. (2000) Significance of melatonin in antioxidative defense system: reactions and products. Biol Signals Recept 9: 137-159.

23. Srinivasan V, Pandi-Perumal SR, Maestroni GJ, Esquifino Al, Hardeland R, et al. (2005) Role of melatonin in neurodegenerative diseases. Neurotox Res 7 293-318.

24. Jin BK, Shin DY, Jeong MY, Gwag MR, Baik HW, et al. (1998) Melatonin protects nigral dopaminergic neurons from 1-methyl-4-phenylpyridinium (MPP+) neurotoxicity in rats. Neurosci Lett 245: 61-64.

25. Dabbeni-Sala F, Di Santo S, Franceschini D, Skaper SD, Giusti P (2001) Melatonin protects against 6-OHDA-induced neurotoxicity in rats: a role for mitochondrial complex I activity. FASEB J 15: 164-170.

26. Behl C, Davis JB, Lesley R, Schubert D (1994) Hydrogen peroxide mediates amyloid beta protein toxicity. Cell $77:$ 817-827.

27. Gupta YK, Gupta M, Kohli K (2003) Neuroprotective role of melatonin in oxidative stress vulnerable brain. Indian J Physiol Pharmacol 47: 373-386.

28. Manev H, Uz T, Kharlamov A, Joo JY (1996) Increased brain damage after stroke or excitotoxic seizures in melatonin-deficient rats. FASEB J 10: 15461551.

29. Guerrero JM, Reiter RJ, Ortiz GG, Pablos MI, Sewerynek E, et al. (1997) Melatonin prevents increases in neural nitric oxide and cyclic GMP production after transient brain ischemia and reperfusion in the Mongolian gerbil (Meriones unguiculatus). J Pineal Res 23: 24-31.

30. Nagai R, Watanabe K, Wakatsuki A, Hamada F, Shinohara K, et al. (2008) Melatonin preserves fetal growth in rats by protecting against ischemia/ reperfusion-induced oxidative/nitrosative mitochondrial damage in the placenta. J Pineal Res 45: 271-276.

31. Zou MH, Shi C, Cohen RA (2002) Oxidation of the zinc-thiolate complex and uncoupling of endothelial nitric oxide synthase by peroxynitrite. J Clin Invest 109: 817-826.

32. Han F, Tao RR, Zhang GS, Lu YM, Liu LL, et al. (2011) Melatonin ameliorates ischemic-like injury-evoked nitrosative stress: Involvement of HtrA2/PED pathways in endothelial cells. J Pineal Res 50: 281-291.

33. Cardoso FL, Brites D, Brito MA (2010) Looking at the blood-brain barrier: molecular anatomy and possible investigation approaches. Brain Res Rev 64 328-363.

34. Ge S, Song L, Pachter JS (2005) Where is the blood-brain barrier ... really? J Neurosci Res 79: 421-427.

35. Hawkins BT, Davis TP (2005) The blood-brain barrier/neurovascular unit in health and disease. Pharmacol Rev 57: 173-185

36. Hawkins BT, Egleton RD (2006) Fluorescence imaging of blood-brain barrie disruption J Neurosci Methods 151: 262-267. 
Citation: Ahmed MM, Huang JY, Tao RR, Han F (2012) Melatonin: the Weapon Against Oxidative Stress and Nitrosative Stress in Neurovascular Diseases. J Bioanal Biomed S5: 005. doi:10.4172/1948-593X.S5-005

37. Persidsky $Y$, Ramirez SH, Haorah J, Kanmogne GD (2006) Blood-brain barrier: structural components and function under physiologic and pathologic conditions. J Neuroimmune Pharmacol 1: 223-236.

38. Chen HY, Chen TY, Lee MY, Chen ST, Hsu YS, et al. (2006) Melatonin decreases neurovascular oxidative/nitrosative damage and protects against early increases in the blood-brain barrier permeability after transient focal cerebral ischemia in mice. J Pineal Res 41: 175-182.

39. Pei Z, Pang SF, Cheung RT (2003) Administration of melatonin after onse of ischemia reduces the volume of cerebral infarction in a rat middle cerebral artery occlusion stroke model. Stroke 34: 770-775.

40. Murawska-Cialowicz E, Januszewska L, Zuwala-Jagiello J, Milczarska J Zawadzki M, et al. (2008) Melatonin decreases homocysteine level in blood of rats. J Physiol Pharmacol 59: 717-729.

41. Okatani Y, Wakatsuki A, Reiter RJ (2000) Protective effect of melatonin agains homocysteine-induced vasoconstriction of human umbilical artery. Biochem Biophys Res Commun 277: 470-475.

42. Baydas G, Yilmaz O, Celik S, Yasar A, Gursu MF (2002) Effects of certain micronutrients and melatonin on plasma lipid, lipid peroxidation, and homocysteine levels in rats. Arch Med Res 33: 515-519.

43. Barnham KJ, Masters CL, Bush Al (2004) Neurodegenerative diseases and oxidative stress. Nat Rev Drug Discov 3: 205-214.

44. Srinivasan V, Pandi-Perumal SR, Cardinali DP, Poeggeler B, Hardeland R (2006) Melatonin in Alzheimer's disease and other neurodegenerative disorders. Behav Brain Funct 2: 15.

45. Pappolla MA, Ogden-Epker M (2000) Oxidative Stress and the Amyloid Conundrum. What is the Connection? J Alzheimers Dis 2: 79-82.

46. Pappolla MA, Sos M, Omar RA, Bick RJ, Hickson-Bick DL, et al. (1997) Melatonin prevents death of neuroblastoma cells exposed to the Alzheimer amyloid peptide. J Neurosci 17: 1683-1690.

47. Pappolla MA, Simovich MJ, Bryant-Thomas T, Chyan YJ, Poeggeler B, et al (2002) The neuroprotective activities of melatonin against the Alzheimer betaprotein are not mediated by melatonin membrane receptors. J Pineal Res 32 135-142.

48. Bozner P, Grishko V, LeDoux SP, Wilson GL, Chyan YC, et al. (1997) The amyloid beta protein induces oxidative damage of mitochondrial DNA. J Neuropathol Exp Neurol 56: 1356-1362.

49. Poeggeler B, Miravalle L, Zagorski MG, Wisniewski T, Chyan YJ, et al. (2001) Melatonin reverses the profibrillogenic activity of apolipoprotein E4 on the Alzheimer amyloid Abeta peptide. Biochemistry 40: 14995-15001.

50. Hardeland R (2005) Antioxidative protection by melatonin: multiplicity of mechanisms from radical detoxification to radical avoidance. Endocrine 27: $119-130$

51. Hardeland R, Pandi-Perumal SR (2005) Melatonin, a potent agent in antioxidative defense: actions as a natural food constituent, gastrointestinal factor, drug and prodrug. Nutr Metab (Lond) 2: 22.

52. Feng Z, Chang Y, Cheng Y, Zhang BL, Qu ZW, et al. (2004) Melatonin alleviates behavioral deficits associated with apoptosis and cholinergic system dysfunction in the APP 695 transgenic mouse model of Alzheimer's disease. J Pineal Res 37: 129-136.

53. AntolÃín I, Mayo JC, Sainz RM, del Brío Mde L, Herrera F, et al. (2002) Protective effect of melatonin in a chronic experimental model of Parkinson's disease. Brain Res 943: 163-173.

54. Lees AJ (1992) When did Ray Kennedy's Parkinson's disease begin? Mov Disord 7: 110-116.

55. Jellinger KA, Stadelmann $\mathrm{CH}$ (2000) The enigma of cell death in neurodegenerative disorders. J Neural Transm Suppl : 21-36.

56. Mochizuki H, Mori H, Mizuno $Y$ (1997) Apoptosis in neurodegenerative disorders. J Neural Transm Suppl 50: 125-140.

57. Perry TL, Yong VW (1986) Idiopathic Parkinson's disease, progressive supranuclear palsy and glutathione metabolism in the substantia nigra of patients. Neurosci Lett 67: 269-274.
58. Saggu H, Cooksey J, Dexter D, Wells FR, Lees A, et al. (1989) A selective increase in particulate superoxide dismutase activity in parkinsonian substantia nigra. J Neurochem 53: 692-697.

59. Yoritaka A, Hattori N, Uchida K, Tanaka M, Stadtman ER, et al. (1996) Immunohistochemical detection of 4-hydroxynonenal protein adducts in Parkinson disease. Proc Natl Acad Sci U S A 93: 2696-2701.

60. Alam ZI, Daniel SE, Lees AJ, Marsden DC, Jenner P, et al. (1997) A generalised increase in protein carbonyls in the brain in Parkinson's but not incidental Lewy body disease. J Neurochem 69: 1326-1329.

61. Alam ZI, Jenner A, Daniel SE, Lees AJ, Cairns N, et al. (1997) Oxidative DNA damage in the parkinsonian brain: an apparent selective increase in 8-hydroxyguanine levels in substantia nigra. J Neurochem 69: 1196-1203.

62. Perier C, Bové J, Dehay B, Jackson-Lewis V, Rabinovitch PS, et al. (2010) Apoptosis-inducing factor deficiency sensitizes dopaminergic neurons to parkinsonian neurotoxins. Ann Neurol 68: 184-192.

63. Fornai F, Schlüter OM, Lenzi P, Gesi M, Ruffoli R, et al. (2005) Parkinsonlike syndrome induced by continuous MPTP infusion: convergent roles of the ubiquitin-proteasome system and alpha-synuclein. Proc Natl Acad Sci U S A 102: 3413-3418.

64. Dexter DT, Wells FR, Lees AJ, Agid F, Agid Y, et al. (1989) Increased nigra iron content and alterations in other metal ions occurring in brain in Parkinson's disease. J Neurochem 52: 1830-1836.

65. Zareba M, Bober A, Korytowski W, Zecca L, Sarna T (1995) The effect of a synthetic neuromelanin on yield of free hydroxyl radicals generated in model systems. Biochim Biophys Acta 1271: 343-348.

66. Ben-Shachar D, Youdim MB (1990) Selectivity of melaninized nigra-striata dopamine neurons to degeneration in Parkinson's disease may depend on iron-melanin interaction. J Neural Transm Suppl 29: 251-258.

67. Chiueh CC, Burns RS, Markey SP, Jacobowitz DM, Kopin IJ (1985) Primate model of parkinsonism: selective lesion of nigrostriatal neurons by 1-methyl4-phenyl-1,2,3,6-tetrahydropyridine produces an extrapyramidal syndrome in rhesus monkeys. Life Sci 36: 213-218.

68. Reiter RJ, Cabrera J, Sainz RM, Mayo JC, Manchester LC, et al. (1999) Melatonin as a pharmacological agent against neuronal loss in experimental models of Huntington's disease, Alzheimer's disease and parkinsonism. Ann N Y Acad Sci 890: 471-485.

69. Acuña-Castroviejo D, Coto-Montes A, Gaia Monti M, Ortiz GG, Reiter RJ (1997) Melatonin is protective against MPTP-induced striatal and hippocampa lesions. Life Sci 60: PL23-29.

70. Mayo JC, Sainz RM, Uria H, Antolin I, Esteban MM, et al. (1998) Melatonin prevents apoptosis induced by 6-hydroxydopamine in neuronal cells: implications for Parkinson's disease. J Pineal Res 24: 179-192.

71. Escames G, León J, López LC, Acuña-Castroviejo D (2004) Mechanisms of $\mathrm{N}$-methyl-D-aspartate receptor inhibition by melatonin in the rat striatum. $J$ Neuroendocrinol 16: 929-935

72. Mathur R, Gupta YK (1999) Adenosinergic and dopaminergic interaction in nigrostriatum in $\mathrm{FeCl} 3$-induced model of parkinsonism in rats. Methods Find Exp Clin Pharmacol 21: 435-439.

73. Naidu PS, Singh A, Kaur P, Sandhir R, Kulkarni SK (2003) Possible mechanism of action in melatonin attenuation of haloperidol-induced orofacial dyskinesia. Pharmacol Biochem Behav 74: 641-648.

74. Acuña-Castroviejo D, Martín M, Macías M, Escames G, León J, et al. (2001) Melatonin, mitochondria, and cellular bioenergetics. J Pineal Res 30: 65-74.

75. Martín M, Macías M, Escames G, León J, Acuña-Castroviejo D (2000) Melatonin but not vitamins $C$ and $E$ maintains glutathione homeostasis in t-butyl hydroperoxide-induced mitochondrial oxidative stress. FASEB J 14 1677-1679.

76. Gilgun-Sherki Y, Rosenbaum Z, Melamed E, Offen D (2002) Antioxidan therapy in acute central nervous system injury: current state. Pharmacol Rev 54: $271-284$

77. Chauhan A, Chauhan V (2006) Oxidative stress in autism. Pathophysiology 13: 171-181. 
Citation: Ahmed MM, Huang JY, Tao RR, Han F (2012) Melatonin: the Weapon Against Oxidative Stress and Nitrosative Stress in Neurovascular Diseases. J Bioanal Biomed S5: 005. doi:10.4172/1948-593X.S5-005

78. Skaper SD, Floreani M, Ceccon M, Facci L, Giusti P (1999) Excitotoxicity, oxidative stress, and the neuroprotective potential of melatonin. Ann N Y Acad Sci 890: 107-118.

79. Mitsutomi N, Akashi C, Odagiri J, Matsumura Y (1999) Effects of endogenous and exogenous nitric oxide on endothelin-1 production in cultured vascular endothelial cells. Eur J Pharmacol 364: 65-73.

80. Koh PO (2008) Melatonin regulates nitric oxide synthase expression in ischemic brain injury. J Vet Med Sci 70: 747-750.

81. Reiter RJ (1991) Melatonin: that ubiquitously acting pineal hormone. Physiology 6: 223-227.

82. Stasica P, Ulanski P, Rosiak JM (1998) Melatonin as a hydroxyl radical scavenger. J Pineal Res 25: 65-66.

83. Stasica P, Ulanski P, Rosiak JM (1998) Reaction of melatonin with radicals in deoxygenated aqueous solutions. J Radioanal Nucl Chem 232: 107-113.

84. Tan DX, Manchester LC, Reiter RJ, Plummer BF, Limson J, et al. (2000) Melatonin directly scavenges hydrogen peroxide: a potentially new metabolic pathway of melatonin biotransformation. Free Radic Biol Med 29: 1177-1185.

85. Mahal HS, Sharma HS, Mukherjee T (1999) Antioxidant properties of melatonin: a pulse radiolysis study. Free Radic Biol Med 26: 557-565.

86. Hardeland R, Reiter RJ, Poeggeler B, Tan DX (1993) The significance of the metabolism of the neurohormone melatonin: antioxidative protection and formation of bioactive substances. Neurosci Biobehav Rev 17: 347-357.

87. Reiter RJ, Tan DX, Poeggeler B, Menendez-Pelaez A, Chen LD, et al. (1994) Melatonin as a free radical scavenger: implications for aging and age-related diseases. Ann N Y Acad Sci 719: 1-12.

88. Reiter RJ, Tan DX, Manchester LC, Qi W (2001) Biochemical reactivity of melatonin with reactive oxygen and nitrogen species: a review of the evidence. Cell Biochem Biophys 34: 237-256.

89. Reiter R, Tang L, Garcia JJ, Muñoz-Hoyos A (1997) Pharmacological actions of melatonin in oxygen radical pathophysiology. Life Sci 60: 2255-2271.

90. Menendez-Pelaez A, Poeggeler B, Reiter RJ, Barlow-Walden L, Pablos MI, et al. (1993) Nuclear localization of melatonin in different mammalian tissues: immunocytochemical and radioimmunoassay evidence. J Cell Biochem 53: 373-382.

91. Antón-Tay F, Martínez I, Tovar R, Benítez-King G (1998) Modulation of the subcellular distribution of calmodulin by melatonin in MDCK cells. J Pineal Res 24: $35-42$.
92. Leon J, Acuña-Castroviejo D, Sainz RM, Mayo JC, Tan DX, et al. (2004) Melatonin and mitochondrial function. Life Sci 75: 765-790.

93. Rodriguez C, Mayo JC, Sainz RM, Antolín I, Herrera F, et al. (2004) Regulation of antioxidant enzymes: a significant role for melatonin. J Pineal Res 36: 1-9.

94. Gulcin I, Beydemir S, Hisar O, Köksal E, Reiter RJ (2009) Melatonin administration increases antioxidant enzymes activities and reduces lipid peroxidation in the rainbow trout ( Oncorhynchus mykiss, Walbaum) erythrocytes. Turk J Vet Anim Sci 33: 241-245

95. Berg RM, Møller K, Bailey DM (2011) Neuro-oxidative-nitrosative stress in sepsis. J Cereb Blood Flow Metab 31: 1532-1544.

96. Han F, Chen YX, Lu YM, Huang JY, Zhang GS, et al. (2011) Regulation of the ischemia-induced autophagy-lysosome processes by nitrosative stress in endothelial cells. J Pineal Res 51: 124-135.

97. Huerto-Delgadillo L, AntÃn-Tay F, BenÃtez-King G (1994) Effects of melatonin on microtubule assembly depend on hormone concentration: role of melatonin as a calmodulin antagonist. J Pineal Res 17: 55-62.

98. Chalbot S, Zetterberg H, Blennow K, Fladby T, Grundke-lqbal I, et al. (2009) Cerebrospinal fluid secretory $\mathrm{Ca} 2+-$ dependent phospholipase $\mathrm{A} 2$ activity is increased in Alzheimer disease. Clin Chem 55: 2171-2179.

99. Wang KK, Larner SF, Robinson G, Hayes RL (2006) Neuroprotection targets after traumatic brain injury. Curr Opin Neurol 19: 514-519.

100. Solà C, Barrón S, Tusell JM, Serratosa J (2001) The Ca2+/calmodulin system in neuronal hyperexcitability. Int J Biochem Cell Biol 33: 439-455.

101. Silva CL, Tamura EK, Macedo SM, Cecon E, Bueno-Alves L, et al. (2007) Melatonin inhibits nitric oxide production by microvascular endothelial cells in vivo and in vitro. Br J Pharmacol 151: 195-205.

102. Kilic E, Kilic U, Reiter RJ, Bassetti CL, Hermann DM (2005) Tissueplasminogen activator-induced ischemic brain injury is reversed by melatonin role of iNOS and Akt. J Pineal Res 39: 151-155.

103. Tao RR, Huang JY, Shao XJ, Ye WF, Tian Y, et al. (2012) Ischemic injury promotes Keap1 nitration and disturbance of antioxidative responses in endothelial cells: a potential vasoprotective effect of melatonin. J Pineal Res.

104. García JJ, Piñol-Ripoll G, Martínez-Ballarín E, Fuentes-Broto L, Miana-Mena FJ, et al. (2011) Melatonin reduces membrane rigidity and oxidative damage in the brain of SAMP8 mice. Neurobiol Aging 32: 2045-2054.

105. Hardeland R (2011) Melatonin and its metabolites as anti-nitrosating and antinitrating agents. J Exp Integr Med 1: 67-81.

This article was originally published in a special issue, Biomedicine Pharmacotherapy handled by Editor(s). Dr. Antonio Di leva, Medical University of Vienna, Austria 